\title{
The Hidden Costs of War: Exposure to Armed Conflict and Birth Outcomes
}

\author{
Florencia Torche, ${ }^{a}$ Uri Shwed ${ }^{b}$
}

a) New York University; b) Ben Gurion University of the Negev

Abstract: Research suggests that prenatal exposure to environmental stressors has negative effects after birth. However, capturing causal effects is difficult because exposed women may be selected on unobserved factors. We use the 2006 Israel-Hezbollah war as a natural experiment and a siblings fixed-effects methodology to address unobserved selectivity by comparing exposed and unexposed births of the same mother. Findings indicate that exposure to war in early and mid-pregnancy lowers birth weight and increases the probability of low birth weight. The effect is not driven by geographic sorting, migration, or increased miscarriages. Given that birth weight predicts health, developmental, and socioeconomic outcomes, prenatal exposure to acute stress may have long-term effects over the life course.

Keywords: prenatal stress; birth weight; natural experiment; fetal origins

Citation: Torche, Florencia, and Uri Shwed. 2015. "The Hidden Costs of War: Exposure to Armed Conflict and Birth Outcomes." Sociological Science 2: 558-581.

Received: April 15, 2015

Accepted: May 21, 2015

Published: December 7, 2015

Editor(s): Jesper Sørensen, Olav Sorenson

DOI: $10.15195 /$ v2.a27

Copyright: (C) 2015 The Author(s). This open-access article has been published under a Creative Commons Attribution License, which allows unrestricted use, distribution and reproduction, in any form, as long as the original author and source have been credited. (C) (i)

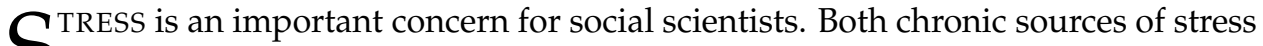
$\mathcal{S}$ such as the strain associated with poverty or racial discrimination and acute sources of stress such as being the victim of a crime, losing a loved one, or being laid off are prevalent in contemporary societies. Recent research focuses on chronic stress resulting from persistent, continuous or cumulative difficult or demanding exposures. This attention is certainly warranted. Chronic stress has been shown to be harmful to health and to be acutely stratified along socioeconomic and racial lines (Pearlin 1999; Thoits 1983; Turner 2003; Turner 2010; Turner and Avison 2003; Turner, Wheaton, and Lloyd 1995). However, acute stress may also be harmful especially if experienced during critical developmental stages such as the prenatal period (Seckl 1998; Knudsen et al. 2006). This article examines the effect of in-utero exposure to an acute environmental stressor on the first observable outcomes after birth—birth weight and gestational age. These birth outcomes capture endowments at the "starting gate of life" (Conley, Strully, and Bennett 2003) and predict physical and mental health, cognitive development, educational attainment, and economic wellbeing over the life course (Barker et al. 1993; Boardman et al. 2002; Behrman and Rosenzweig 2004; Black et al. 2007; Palloni 2006).

The study of the consequences of prenatal stress is not new. There are hundreds of studies reporting an association between prenatal stress and negative outcomes at birth and during childhood (for reviews, see Austin and Leade 2000; Beydoun and Saftlas 2008; De Weerth and Buitelaar 2005; Dunkel-Schetter 2011). However, most of these studies measure stress using individual self-reports about major life events, statetrait anxiety inventories, or chronic stress inventories These studies are vulnerable to unobserved selectivity if pregnant women who experience or report high levels of stress are selected on factors such as health status, socioeconomic 
resources, genetic endowments, personality, or social support. Given the difficulty in observing some of these factors, it is impossible to separate the effect of stress exposure from its unobserved correlates. Researchers are acutely aware of this issue. As a review of the field candidly states, "there could be other... effects that account for these associations; ranging from shared genetic variance to indirect behavioral mechanisms... a number of third variables (remain) that might explain the apparent association" (Talge, Neal, and Glover 2007).

To alleviate this problem, we combine a natural experiment-the 2006 IsraelHezbollah War-with causal inference techniques. In May 2000, Israel withdrew its forces from Lebanon, ending 18 years of occupation and mutual bloodshed. Between 2000 and 2006, Hezbollah occasionally attacked Israeli military targets around Israel's border, but the attacks had minimal effects on civilian life in northern Israel. One single rocket was launched from Lebanon toward a civilian area in northern Israel over these six years, and in the relative peace, the region flourished. This came to an abrupt end on July 12, 2006, when Hezbollah kidnapped two Israeli border patrol soldiers and severely hit Israeli Defense Forces (IDF) rescue teams. Israel's response culminated in a full-scale war, lasting until August 14,2006.

Several characteristics of the 2006 clash substantiate its use as an instrument for environmental stress. First, the conflict was unexpected to the Israeli population and decision-makers alike. Both the kidnapping of the Israeli soldiers and Hezbollah's capabilities that the war exposed caught the Israeli government by surprise (Winograd et al. 2008). Yet while Hezbollah shocked Israel with the kidnapping attack, the Israeli response also stunned Hezbollah. As Hezbollah Secretary General Hassan Nasrallah indicated after the ceasefire was declared, “We wouldn't have snatched the soldiers if we thought it would spark war" (Alon et al. 2006).

Second, the war was brief, lasting only 33 days, from July 12 to August 14 . Because it was short, unexpected, and unannounced, the affected population experienced the war as an exogenous shock, and families did not have the chance to predict or prepare in advance. These attributes minimize selectivity driven by preemptive migratory or fertility responses. However, selectivity may remain if the exposed population were systematically different from the unexposed population in ways that would shape birth outcomes. To address this potential source of bias, we use birth registry data and link all births of the same mother over a six-year period to implement a sibling fixed-effects model that compares infants prenatally exposed to the war with their unexposed siblings. Within-mother comparisons account for unobserved characteristics of the family or the mother that do not change between births and which may confound the findings.

Third, while Israeli bombings destroyed complete neighborhoods and villages in Lebanon, damage on the Israeli side of the border was limited. The 33 days of violence resulted in 1,183 Lebanese deaths and thousands wounded (Batley, Makhoul, and Latif 2008). On the Israeli side, 119 soldiers were killed, and though approximately 4,000 rockets hit Israel's northern region, only 44 civilians died. While each loss of life is a tragedy, this is a minor toll given an exposed population of approximately 1 million (the war-related fatality rate of approximately 4.4 per 100,000 population compares with a traffic fatality rate of 6.4 per 100,000 and a suicide rate of 9.9 per 100,000 in 2006). Furthermore, the war occasioned no 
serious alteration of infrastructure or services such as electricity, potable water, and healthcare services, no air or water quality damage, and no public health emergency (Israel State Comptroller 2007). While infrastructure and healthcare remained relatively intact, the war and the constant threat of missiles did induce elevated stress and anxiety among the exposed population in northern Israel (Cohen 2008; Palmieri et al. 2008). Given the limited spillover effects of the war on the population living in northern Israel, acute stress and anxiety stand as the main pathway to account for the effect of war exposure on birth outcomes.

\section{The Noxious Effect of Different Types of Stress}

Biological, psychological, and social scientific research on stress and its consequences has expanded over the last decades. Early post-war research was based on a biological stimulus-response model.(Dohrenwend and Dohrenwend 1970; Selye 1956). Stressors were understood as "life events"—distinct, directly measurable circumstances with a limited timeframe, such as experiencing the death of a loved one or being assaulted. This biological perspective focuses exclusively on discrete exposures. An alternative perspective suggests an understanding of stress in which a long process of excessive load and fatigue leads systems to collapse without need of a triggering event. Applied to human populations, this perspective highlights long-term difficult or demanding exposures, emerging for example from economic disadvantage, troubled relationships with family, or experiencing discrimination (Pearlin 1999; Thoits 2010).

This type of persistent exposure came to be known as a source of "chronic" stress (Pearlin et al. 1981) and over time, came to be regarded as particularly toxic. The notion of "allostatic load" - the long-term wear and tear across multiple systems of the organism resulting from continuous, persistent, or cumulative stress exposure ...(McEwen 1998; McEwen and Stellar 1993)—offered a mechanism for the negative effects of chronic stress on health and performance. Research has focused on chronic stress because it has been found to have a stronger negative association with physical and mental health and to be more stratified along socioeconomic lines than life events and other acute stressors (Pearlin 1999; Thoits 1983; Turner 2003; Turner 2010; Turner and Avison 2003; Turner, Wheaton, and Lloyd 1995). But recent findings from biological sciences suggest that exposure to acute stressors could also be harmful when it occurs during the prenatal period, which is characterized by sensitive and critical developmental stages that determine future capabilities. Events during these periods may induce long-term alterations in the developing brain and the physiological systems that shape health and performance throughout the life course (Shonkoff 2010).

To date, most research on stress relies on self-reports of naturally occurring and subjectively assessed stressful circumstances. The most widely used life-event inventories ask people whether they have been exposed to negative events such as the death of a spouse, being fired at work, or a personal injury (Holmes and Rahe 1967). Chronic stress inventories, in turn, capture persistent exposures with items such as: too much is expected of you by others; your spouse does not understand you; and you want to change job or careers but don't feel you can (Wheaton 1997). 
While much has been learned from these measures, one limitation of this approach is that both experiencing these stressors and the subjective perception of them is likely related to unobserved individual characteristics with an independent effect on health and wellbeing. While subjective experience and perception is an important topic in its own right, if the question of interest is the causal effect of stress exposure, then plausibly exogenous sources of stress are necessary. This is what this natural experiment seeks to provide.

An emerging literature using natural experiments such as natural disaster, terrorist attack, collective mourning, violent conflict, or discrimination to examine the causal effect of prenatal stress on birth outcomes exists (Catalano and Hartig 2001; Eskenazi et al. 2007; Mansour and Rees 2012; Lauderdale 2006; Torche 2011). This literature faces three important challenges: (1) finding truly exogenous sources of stress; (2) meeting the exclusion restriction requirement that the effect be driven by stress only rather than alternative pathways of influence; and (3) gaining access to data sources with no selectivity and minimal measurement error. This article builds on this literature and addresses these challenges to the extent that is possible in a quasi-experimental setting.

\section{Stress and Birth Outcomes: Pathways, Timing, and Proximate Mechanisms}

We examine the potential effect of stress exposure in the earliest possible stage of the life course - the prenatal period-and its consequences on birth outcomes. The mechanisms linking prenatal stress exposure to birth outcomes are neuroendocrine, immune/inflammatory, vascular, and behavioral (Beydoun and Saftlas 2008; Dunkel Schetter 2011; Hobel, Goldstein, and Barrett 2008). The primary hypothesized mechanism is neuroendocrine. A pregnant woman's response to a stressor activates the hypothalamic-pituitary-adrenal (HPA) axis, triggering the production of corticotropin-releasing hormone $(\mathrm{CRH})$, adrenocorticotropic hormone (ACTH), and cortisol in the mother, the placenta, and the fetus. High levels of these stress hormones in turn may result in reduced gestational age and lower birth weight (Dunkel, Schetter, and Glynn 2011; Hobel and Culhane 2003; Lockwood 1999).

The timing of this neuroendocrine process is consequential, with most evidence suggesting stronger effect on birth outcomes when stress exposure occurs in the first or second trimester of gestation (de Weerth and Buitelaar 2005; Glynn et al. 2001; Hobel, Goldstein, and Barrett 2008). Early elevation-as early as between the fifteenth and twentieth weeks of gestation-has been found to predict eventual preterm labor months after the exposure (Holzman et al. 2001; Wadhwa et al. 2004). The mechanism appears to be epigenetic. Early pregnancy CRH gene expression in the placenta does not induce labor immediately but rather sets a biological clock for eventual early delivery months after exposure to the stressor (McLean et al. 1995).

Stress exposure can also alter inflammatory and immune functions, which in turn may affect birth outcomes. Stress appears to induce inflammatory processes in pregnancy (Coussons-Read et al. 2005), a factor in preterm birth(Goldenberg, 
Hauth, and Andrews 2000). Stress hormones also appear to be associated with immunosuppression, which in turn increases the risk of infection (Coussons-Read et al. 2005; Elenkov et al. 1999). Another pathway linking maternal stress and birth weight is maternal behaviors. Stress may lead to behaviors including excessive use of tobacco, alcohol, or caffeine, or change in diet (Lobel et al. 2008; Reichman and Teitler 2003), which may in turn affect birth outcomes (Neggers et al. 2006). Behavioral responses to acute stressors could also be beneficial, for instance increasing the early initiation and use of prenatal care in an attempt to protect the pregnancy (Torche and Villarreal 2014).

There are two proximate determinants of birth weight: weeks of gestation and intra-uterine fetal growth. The distinction between them is important because these determinants have different etiologies and different consequences for later development ...(Hobel, Goldstein, and Barrett 2008; Paneth 1995). Most research has found an effect of prenatal stress on length of gestation (Dunkel-Schetter 2011), but some evidence suggests an effect on fetal growth as well (Wadhwa et al. 2004). In sum, a body of biological research offers hypotheses about a negative effect of acute stress exposure on birth weight, its timing, and its proximate mechanism, which this article will assess.

\section{Data and Methods}

The source for the analysis is a data set of all births in Israel between 2003 and 2009 prepared by the Israeli Central Bureau of Statistics (CBS) per the authors' request. This data set combines information about every birth in the country with information from the national registry of vital statistics. The Ministry of Health data set is based on birth certificates. The national registry database is used to cross-check this information and to add maternal characteristics not included in the birth certificate. Crucially for our analysis, the birth certificate includes information on the mother's habitual place of residence. We code maternal residence by natural region, administrative units roughly equivalent to counties in the U.S. context, with an average population of approximately 140,000.

In order to measure exposure to the war, we created a data set with information on every missile that fell on Israeli territory during the war and the day of each attack. Such information is hard to obtain, as official sources do not disclose the exact locations that were hit, and unofficial sources are inaccurate. Furthermore, official sources tend to report missile launches while newspapers report hits, and many missiles are launched but never hit Israel (i.e., they hit the Mediterranean Sea or Lebanon). The most comprehensive source is the Winograd report, produced by a government-appointed commission of experts tasked with investigating the events associated with the war, but even this report lacks information on exact locations.

We collected information from three major Israeli newspapers (Yediot, Haaretz, and Maariv), and two websites (Ynet and Haaretz), and cross-checked the total number of missiles per day with the Winograd report. Figures vary somewhat across newspapers. Overall, Yediot consistently reported more missiles and in greater detail, so we rely on Yediot. The total number of missiles reported by Yediot 
and Winograd are similar on only 25 percent of days. After information is collapsed at the level of the natural region the differences disappear. This indicates that discrepancies emerge from missiles recorded as falling in adjacent localities within the same natural region. The missile data set was linked to the birth data set by means of the natural region of the mother's residence.

Israel is divided into 50 natural regions, of which 40 are included in the analysis and 16 (18 percent of the national population) were hit during the war. We excluded 10 natural regions (about 26 percent of the national population) in the southern part of Israel or in the West Bank because these areas experienced several periods of ongoing missile attacks from Gaza (southern Israel) and civil conflict and attacks (the West Bank). As a result, they arguably were exposed to armed conflict at some point, or persistently, over the period considered and do not provide an adequate baseline for comparison. Figure 1 offers a map of the exposed region in northern Israel, the unexposed area in the center, and the excluded regions. Our analytical sample selects all mothers with at least two births over the 2003-2009 period. The sample consists of 232,521 mothers with more than one birth, for a total of 507,275 births.

\section{Variables}

We define the treatment based on geographical and temporal variation. Geographical exposure is captured by a dichotomous variable that distinguishes natural regions that were hit by missiles from those that were not. While a more detailed classification based on the number or frequency of missiles would be ideal, this is prevented due to measurement error and sample size constraints. Temporal exposure to the war was constructed from information on date of birth and gestational age and was measured using two formulations. First, we distinguish between five periods: (1) babies conceived more than 42 weeks prior to the war; ${ }^{1}(2-4)$ babies exposed to the war during each trimester of gestation; and (5) babies conceived after the war. An alternative formulation distinguishes month of exposure, allowing us to conduct a detailed analysis of the timing of effects.

The main dependent variables are birth weight (grams) and gestational age (weeks since last menses). Birth weight was also dichotomized, distinguishing low-birth weight babies (less than 2,500 grams). Though arbitrary, this category identifies births most at risk of mortality, morbidity, and developmental problems (Conley, Stully, and Bennett 2003). Measures of birth weight are recorded by the medical professional attending the delivery and reported with little error, but gestational age may be less reliable (Behrman and Stith-Butler 2007). Reduced reliability will result in bias only if there is a systematic association between underor overestimation and treatment allocation, a very unlikely occurrence. In the most likely scenario of random misestimation, measurement error in the dependent variable will not induce bias.

The following birth-specific controls were included: whether the birth is single or multiple; sex; parity; mother's ethnicity (i.e., Jew or Arab); mother's marital status (married, single, divorced, or widowed); and mother's age and its squared term. We also control for quarter of conception of each birth to rule out confounding 


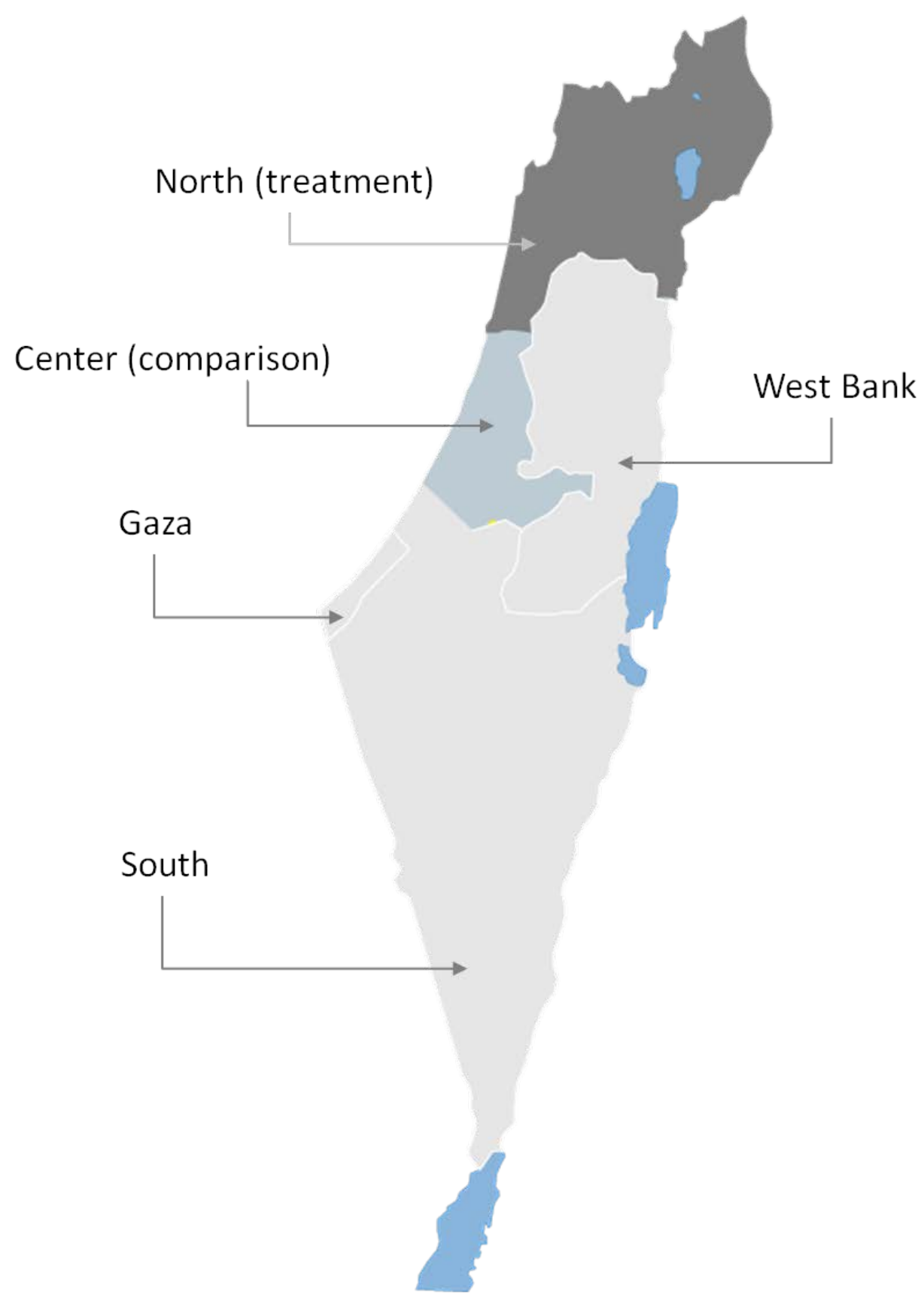

Figure 1: Map of Study Population We compare births in Northern Israel (dark gray) which were in the range of Hezbollah's missiles in 2006, to the out of reach regions in the Center, Sharon, and Jerusalem regions (pale blue), excluding the South and the West Bank (pale gray) which were subjected to a host of armed conflict events in the study years. Areas in bright blue identify bodies of water. 
from seasonality in birth weight (Chodick et al. 2007). Given that the fixed-effects formulation controls only for birth-invariant unobserved attributes of the mother (see below), adding these birth-specific controls reduces the chances of a spurious effect. The data set does not include information on socioeconomic standing but includes information on ethnicity (Arab or Jew), which we use to examine potential heterogeneity in the effect of stress exposure.

\section{Methods}

The causal effect of war exposure on the outcomes of interest—birth weight and gestational age-was obtained by comparing infants prenatally exposed to the war with their unexposed siblings. Let

$$
y_{i j}=\beta_{1} E_{i j k}+\mathbf{x}_{i j}{ }^{\prime} \beta_{2}+u_{j}+e_{i j},
$$

where $i$ identifies births, $j$ identifies mothers, and $k$ identifies time of gestation (alternatively measured in trimesters or months). $Y_{i j}$ is the outcome for infant $i$ born to mother $j ; \mathrm{E}_{i j k}$ is an indicator that takes the value 1 if the infant was exposed to the war during period of gestation $k ; \boldsymbol{X}_{i j}$ is a vector of mother and birth characteristics; $u_{j}$ captures unmeasured mother-specific attributes; and $e_{i j}$ is a random disturbance. The term $u_{j}$ includes unobserved maternal, family, and genetic characteristics potentially correlated with exposure and with the outcome of interest (e.g., mother's health endowments, socioeconomic resources, social support).

The central parameter of interest is $\beta_{1}$. Cross-sectional estimates of $\beta_{1}$ would be biased because no controls are included for factors in $u$, if these factors are correlated with both war exposure and birth outcomes. A mother fixed-effect model was implemented to alleviate this problem. This strategy amounts to estimation in birth-specific deviation from the mother-specific means for all variables. Motherspecific means are expressed as:

$$
\bar{y}_{j}=\beta_{1} \bar{E}_{j}+\bar{x}_{j}^{\prime} \beta_{2}+\bar{u}_{j}+\bar{e}_{j} .
$$

Subtracting Equation (2) from Equation (1) yields the fixed-effect estimator:

$$
\left(y_{i j}-\bar{y}_{j}\right)=\beta_{1}\left(E_{i j k}-\bar{E}_{j}\right)+\left(\mathbf{x}_{i j}-\bar{x}_{j}\right)^{\prime} \beta_{2}+\left(e_{i j}-\bar{e}_{j}\right) .
$$

Because the unobserved mother-specific factors included in $u$ do not vary across siblings, the term drops from the differenced equation. Mother's characteristics $(x)$ that do not change across births are also dropped from this equation. Under the assumption that $\mathrm{e}_{i j}$ is uncorrelated with $\mathrm{E}_{i j k} \beta 1$ is unbiased. The standard errors are corrected for heteroskedasticity and clustered at the mother level

Estimation uses linear regression models for continuous variables and linear probability models for dichotomous dependent variables. Given the sensitive nature of the data all analyses had to be performed on a secure computer in the Israel's Central Bureau of Statistics (CBS) research room located in Jerusalem. Log files were examined and cleared by CBS personnel and then sent to the authors. 


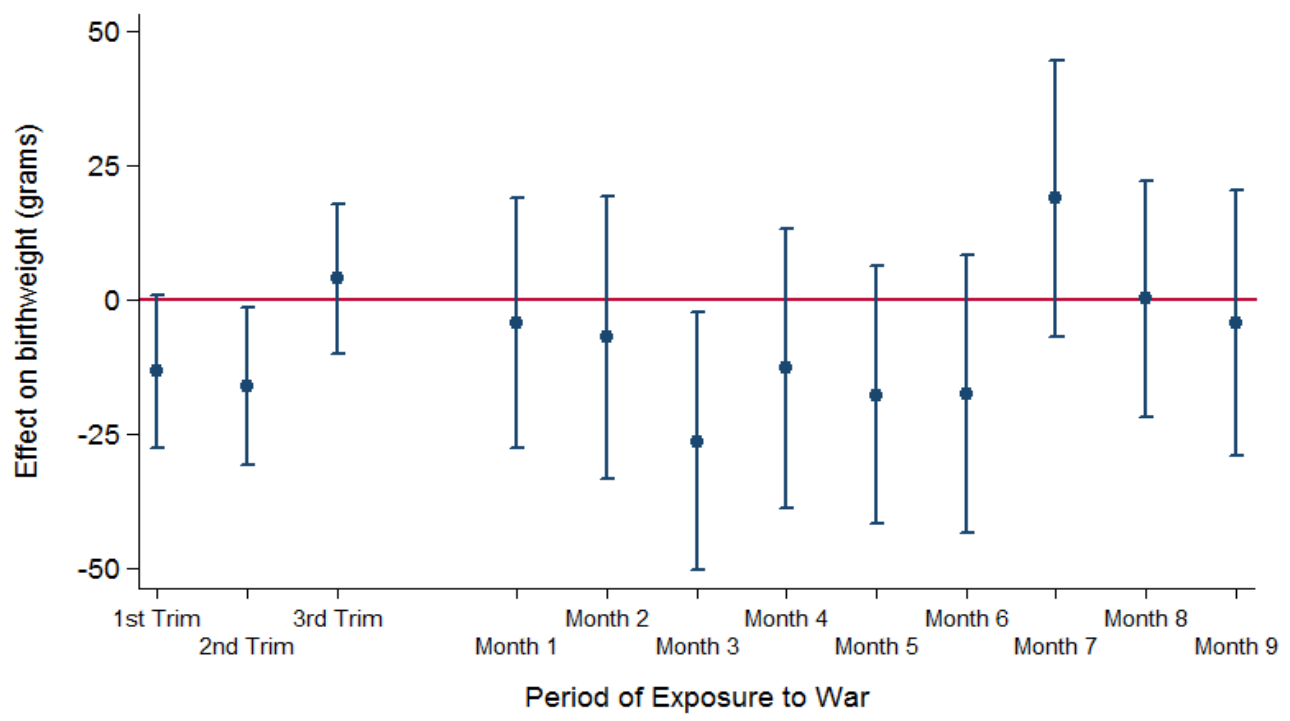

Figure 2: Effect on birthweight (grams) of prenatal exposure to the $2^{\text {nd }}$ Lebanon War across trimester/month of gestation. Shaded dots indicate parameter estimates and vertical bars are the $95 \%$ Confidence Interval. Exposure is captured by a dichotomous variable that distinguishes "natural regions" in Northern Israel that were hit by missiles during the war from those that were not (40 natural regions are included in the analysis of which 16-comprising $18 \%$ of the Israeli population-were hit by missiles). Gestational trimester/month of exposure was defined by counting forward from time of conception as recorded in the birth certificate. Analysis controls for whether the birth is single or multiple, male, parity, mother's ethnicity (Jew, Arab), mother's marital status (married, single, divorced, widow), mothers' age and its squared term, and quarter of conception. Sibling fixed effects linear model. Source: Table A1 in Appendix.

\section{Findings: The Effect of War Exposure on Birth Outcomes}

Figure 2 offers results of the analysis of birth weight using trimester and month of exposure (Table A1 in the appendix offers parameter estimates, standard errors, and significance tests). Exposure to the war in the first and second trimesters of gestation results in significant declines in birth weight—by 13 and 16 grams respectively; exposure in the third trimester of gestation does not have an effect on birth weight. When exposure by month of gestation is examined, results indicate that exposure in months one through six results in a negative effect on birth weight, with the strongest adverse effects focused on month three (with a decline of 28 grams) and months five and six (declines of 18 and 17 grams respectively, although these fail to reach significance at the conventional $p<0.05$ level).

Is a decline of birth weight of approximately 15 grams due to exposure in the first and second trimesters substantively relevant? Our assessment is that it is. The effect captured is an intent-to-treat (ITT) effect measured among all women exposed to the war, not only those who suffered from stress. If it were possible to estimate a treatment-on-the-treated effect (TOT) - the effect only on women who suffered from stress-this effect would be, necessarily, larger. Research measuring 


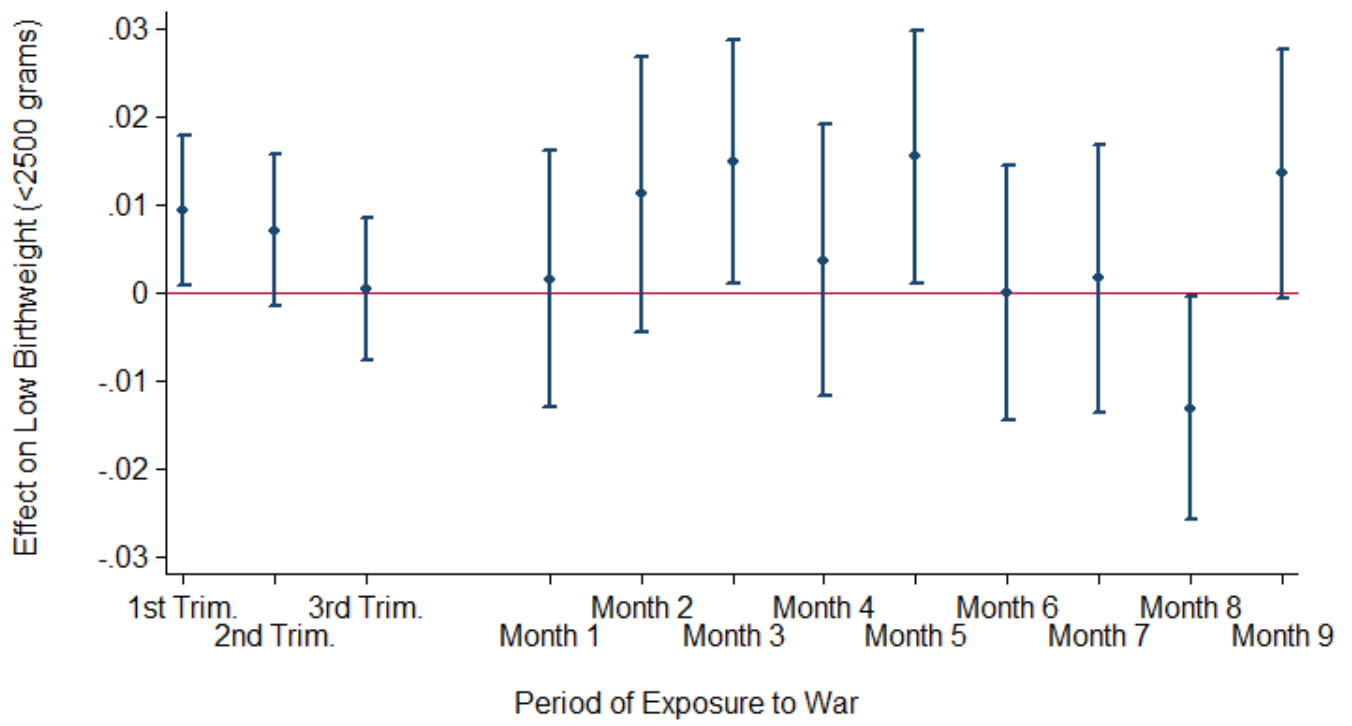

Figure 3: Effect on the probability of low birthweight (less than 2,500 grams) of prenatal exposure to the $2^{\text {nd }}$ Lebanon War across trimester/month of gestation. Shaded dot indicates parameter estimate and vertical bar is the $95 \%$ Confidence Interval. Sibling fixed effects linear probability model. Source: Table A1 in Appendix.

ITT effects of other environmental stressors as well as major policy interventions provide useful benchmarks. For example, Mansour and Rees (2012) found an ITT of about five grams among educated mothers resulting from the al-Aqsa intifada in Palestine using a similar fixed-effects methodology, and Torche (2011) finds an ITT of exposure to a major earthquake in the first trimester of gestation of about 50 grams Hoynes, Page, and Stevens (2011) found an ITT of the Supplemental Nutrition Program for Women, Infants, and Children (WIC) on birth weight of 2.5 grams among disadvantaged women Almond, Hoynes, and Schanzenbach (2011) found an ITT of the Food Stamp Program on birth weight of approximately 2.5 grams for whites and four grams for blacks, and a TOT effect of between 15 and 20 grams for whites and between 13 to 42 grams for blacks. Compared to these environmental stressors and policy interventions, the effects we find in Israel appear substantively relevant.

However, the exposure to armed conflict could have moved birth weight within a plausibly normal range, without affecting the proportion of low-weight infants most at risk of health and developmental problems. Figure 3 (Table A1 in the appendix) shows that this is not the case. Figure 3 shows a significant effect of exposure to war on the probability of low-weight births. First trimester exposure results in an increase in the proportion of low-weight births by 0.9 percentage points; exposure in the second trimester induces an increase of 0.7 percentage points. Given that the proportion of low-weight births in Israel approximates eight percent, this amounts to substantial increases of 11 and nine percent respectively from this proportion. The analysis by month of exposure confirms that the most adverse effects occur in months three and five, with a large increase in low birth weight (by 1.5 percentage points) associated with exposure in either month. As a 

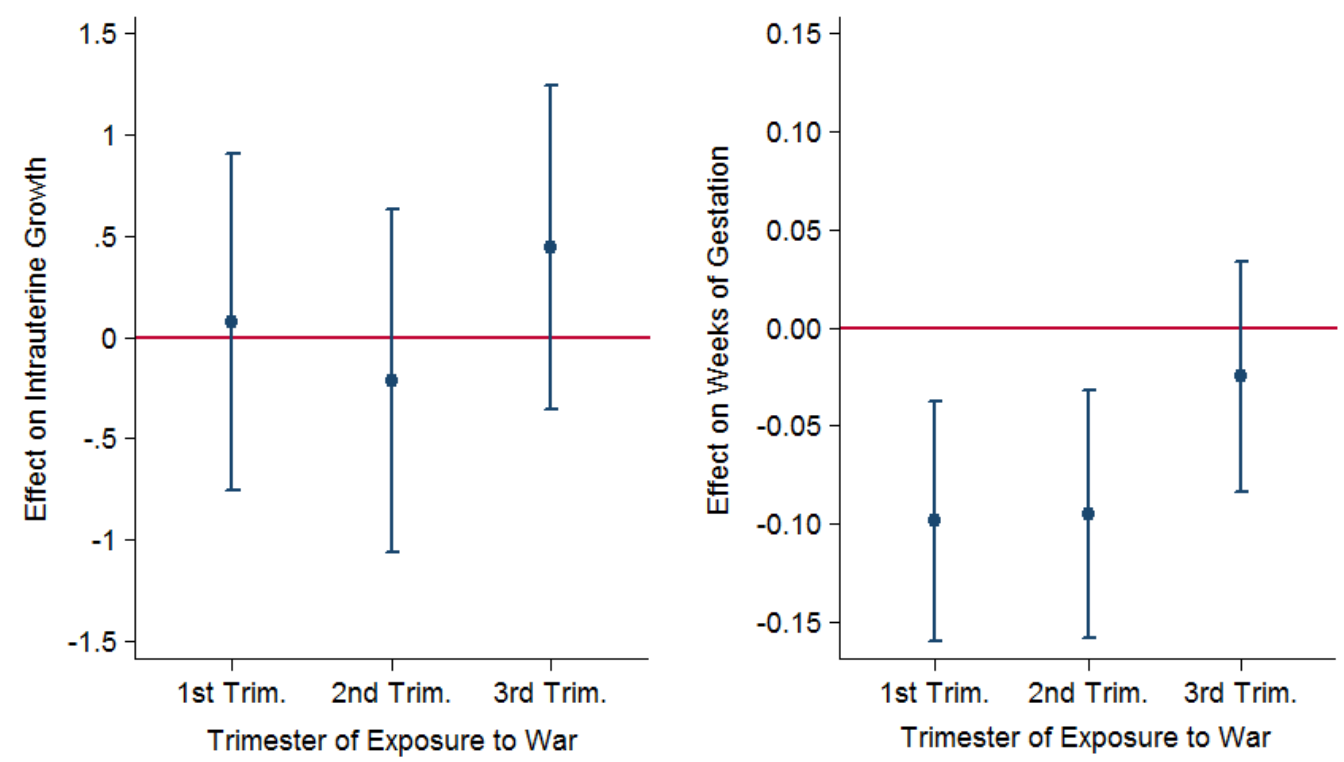

Figure 4: Effect of prenatal exposure to the $2^{\text {nd }}$ Lebanon War on intrauterine fetal growth (sex-specific percentile weight for gestational age) and on duration of pregnancy (weeks of gestation) across trimester of gestation. Shaded dot indicates parameter estimate and vertical bar is the $95 \%$ Confidence Interval. Sibling fixed effects linear model. Source: Table A2 in Appendix.

test of robustness, we estimated fixed-effects models for low birth weight using a conditional logit model instead of a linear probability model (Allison 2009:32-39). Results are nearly identical to those obtained from linear probability models (Table A5 in the appendix).

As discussed, the effect of stress exposure on birth weight depends on only two proximate determinants of birth weight: weeks of gestation and intra-uterine growth. In order to explore proximate mechanisms, the effect of war on weeks of gestation and the sex-specific fetal growth percentile by week of gestation is examined in Figure 4 (Table A2 in the appendix). Figure 4 shows that the effects of armed conflict on weeks of gestation mirror the patterns for birth weight, with negative coefficients for exposure in trimesters one and two, and a null effect later in the pregnancy. Detailed analysis by month shows strongest effects in months three and five of gestation (Table A2 in the appendix). In contrast, no effect of war exposure on intra-uterine growth is detected.

In sum, our findings demonstrate a causal link between exposure to the war and birth outcomes. On average, exposed infants are of lower birth weight and more likely to be born low-weight than their unexposed siblings. These findings also offer answers regarding timing and mechanisms of environmental stress exposure before birth. The effect emerges for exposure in the second and in particular in the first trimester, and the proximate mechanism is a reduction in gestational age rather than lower fetal growth. Although our research cannot directly assess more distal mechanisms, this finding is consistent with the hypothesis of an epigenetic 
mechanism in which stress-induced endocrine gene expression in the placenta during early pregnancy sets a clock for early delivery.

The effect found is a population-level average, which may include substantial heterogeneity. The literature suggests that disadvantaged populations may be more strongly affected both because they are more likely to be exposed to harm from environmental stressors and because they are more sensitive to their effects given exposure (Turner, Wheaton, and Lloyd 1995). We lack direct measures of socioeconomic status, but we can distinguish Jewish and Arab ethnicity, which in the Israeli context is correlated with socioeconomic status. Israeli Arabs have lower levels of education, employment, income, and wealth and suffer from residential, educational and occupational segregation and discrimination (Ghanem 1998; LewinEpstein and Semyonov 1992; Okun and Friedlander 2005; Semyonov and LewinEpstein 2011) We exclude the small percentage (approximately four percent) of non-Arab, non-Jewish population, and conduct an analysis stratified by ethnicity.

Among Arabs, the decline in birth weight associated with war exposure reaches 18 grams for exposure in the first trimester and 23 grams for exposure in the second trimester. Comparable figures for Jews are 12 grams each trimester (Figure 5; also Table A3 in the appendix). These differences fail to reach significance at the conventional $p<0.05$ level, so we cannot rule out the null hypothesis of similar effects across ethnic groups.

\section{Causal Effects or Population Selectivity?}

The Second Lebanon war was a short-term and unexpected source of acute stress, but three potential sources of selectivity remain, namely: (1) an increase in spontaneous abortions resulting from exposure to the war; (2) temporary migration during the conflict; (3) and alteration of fertility patterns as a response to the war that would make siblings born after the war an inadequate counterfactual.

Women exposed to the armed conflict may have been more likely to miscarry, particularly by "culling the weakest" gestations (Bruckner and Catalano 2007), thus altering the exposed population. The literature is not conclusive about the effect of maternal exposure to environmental stressors on pregnancy loss, with some studies reporting no effect (Milad 1998; Nelson et al. 2003) and others reporting increased miscarriages (Nepomnaschy et al. 2006).

Direct examination of the effect of war exposure on spontaneous abortion is not possible because information about fetal losses early in pregnancy is notoriously unreliable, as many miscarriages go unreported and even unnoticed. We therefore implement an indirect strategy based on the reasoning that an increase in the proportion of miscarriages or spontaneous abortions resulting from war exposure should induce a decline in birth rate in the exposed area. To test for such an increase, we use an interrupted time series analysis of the number of births (McDowall et al. 1980). Interrupted time series analysis accounts for temporal autocorrelation in the form of trends, cycles, and the tendency for values to remain elevated or depressed after high or low values in time series data, which could confound the effect of exposure (Catalano et al. 2006) The number of births in the exposed area was summarized into a time series of weekly totals, encompassing conceptions 


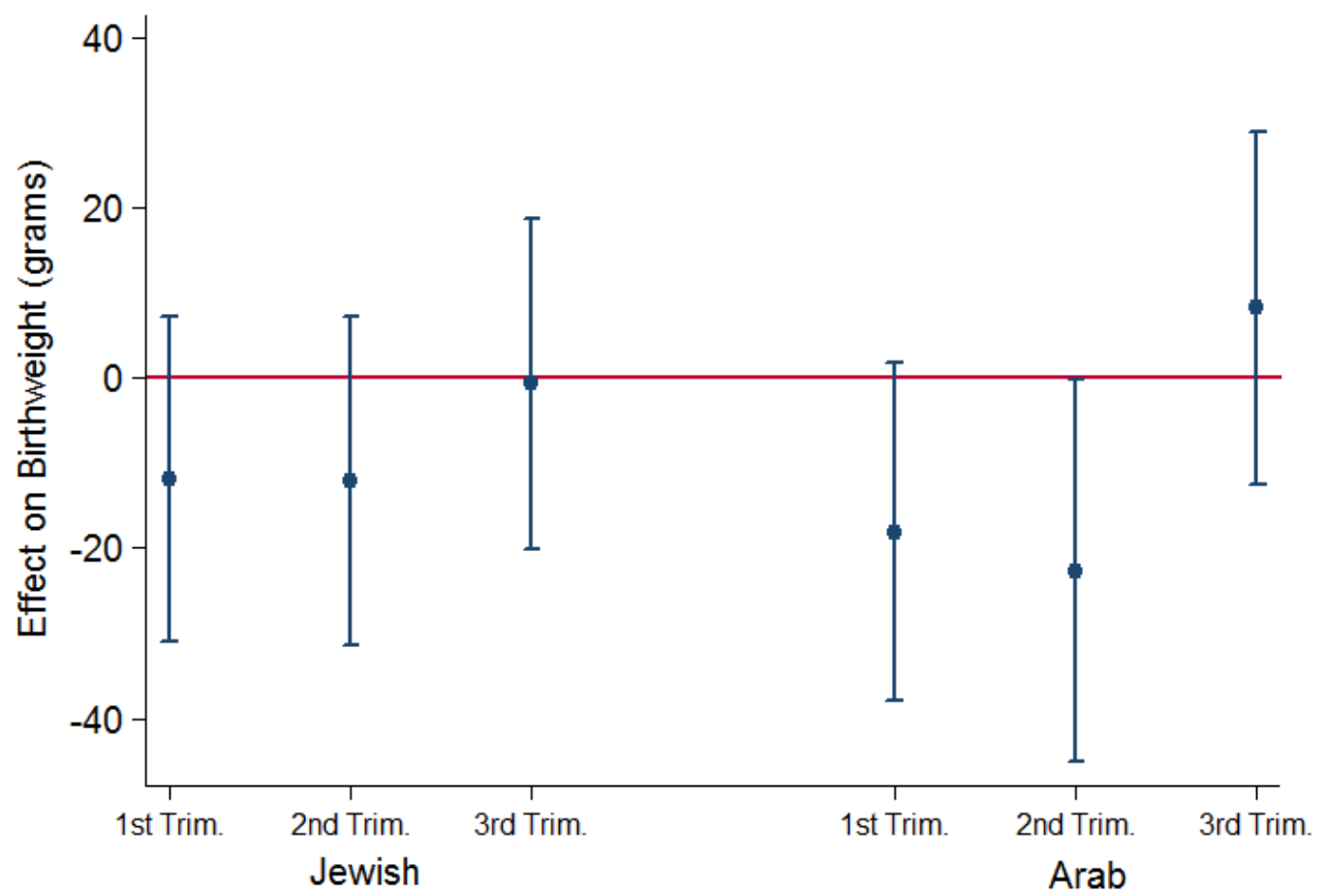

Trimester of War Exposure

Figure 5: Effect on of prenatal exposure to the $2^{\text {nd }}$ Lebanon War on birthweight (grams) across trimester of gestation for Jewish and Arab population. Shaded dot indicates parameter estimate and vertical bar is the 95\% Confidence Interval. Sibling fixed effects linear model. Source: Table A3 in Appendix.

between March 2002 and February 2009, and the war was defined as the interruption. The null hypothesis is that the post-interruption values of the dependent variable (number of births) do not differ from the values expected from the pre-interruption series. A detailed description of the time series analysis is provided in the appendix.

After accounting for trend, seasonality and autocorrelation through an ARIMA model, the effect of war exposure on number of births was evaluated by means of a set of dummies for each month of war exposure capturing the interruption. Results from the interrupted time series analysis are reported in Table 1. The parameter estimates measuring exposure to the Lebanon war in early gestation are very far from statistical significance at the conventional $p<0.05$ level, suggesting that war exposure did not increase fetal losses during pregnancy. While we cannot absolutely rule out an increase in miscarriages as a source of selectivity by using this indirect test, there is no indication of such an effect. Furthermore, it is important to mention that if "culling of the weakest" gestations had indeed occurred, our analysis would underestimate the negative effects of stress on birth outcomes because the most vulnerable gestations would have been lost.

Migration is an alternative source of population selectivity. About one quarter of the population living in northern Israel temporarily left the region to reside with relatives or evacuated to the center or south of the country during the war (Israel 
Table 1: Interrupted time-series ARIMA analysis of the effect of prenatal exposure to the Second Lebanon War on number of births in Northern Israel

Exposed to Lebanon War Month 1 of gestation

Exposed Month 2

Exposed Month 2

$-21.212$

Exposed Month 3

$-6.238$

$(29.468)$

Exposed Month 4

$-9.973$

Exposed Month 5

(38.625)

$-0.641$

(19.892)

Exposed Month 6

Exposed Month 7

13.607

(18.486)

Exposed Month 8

$-24.154$

$(45.092)$

Exposed Month 9

Constant

AR1

Sigma (residual standard error)

Standard errors in parentheses. $* p<.05 ;+p<.01$.

State Comptroller 2007). If the leavers were selected on factors correlated with birth outcomes-for example if more advantaged women had been more likely to leave, leaving behind disadvantaged women - and if the births of the leavers had been observed outside of the exposed area, then the observed effect could be an artifact of changing population composition. The empirical analysis is robust to migration-induced selectivity. Most evacuations lasted less than a week, and virtually all those who fled during the conflict returned to their homes during the war or within a few days of the ceasefire, so they would be coded as residing in the exposed area during the war. More important, birth certificates record the habitual residence of the mother even if she were temporarily absent. This means that even women who gave birth while temporarily away from home during the war were identified by their northern residence, thus correctly being observed as living in the exposed area. 


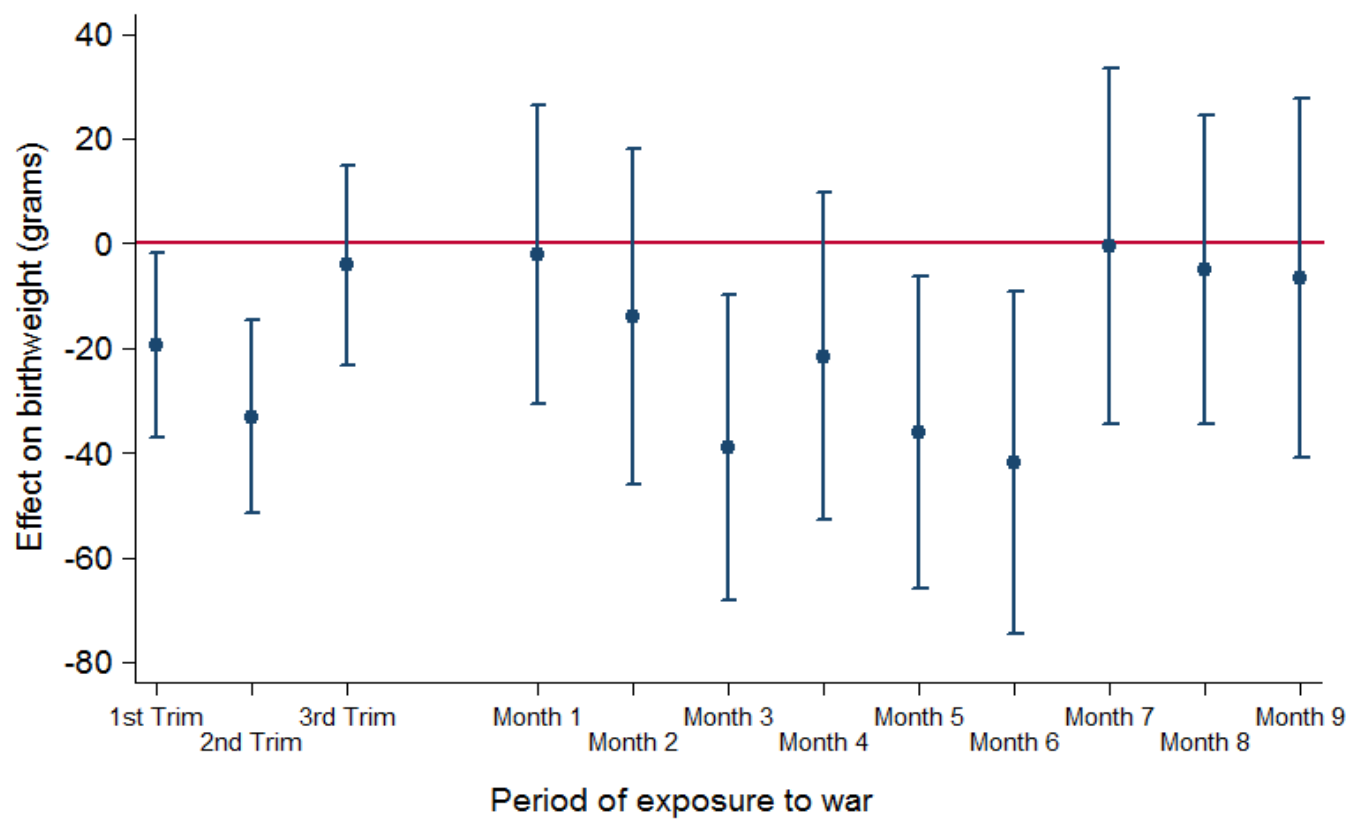

Figure 6: Effect on birthweight (grams) of prenatal exposure to the Second Lebanon War across trimester/month of gestation, excluding siblings born after the war. Shaded dot indicates parameter estimate, and the vertical bar is the 95 percent confidence interval. Analysis controls for whether the birth is single or multiple; sex; parity; mother's ethnicity (Jew or Arab); mother's marital status (married, single, divorced, or widow); mothers' age and its squared term; and quarter of conception. Sibling fixed effects.

Alternatively, some women selected on unobserved attributes may have left the exposed area in anticipation of the conflict. Even though the unexpected and unannounced nature of the war makes anticipatory migration unlikely, we examine this possibility. Ancillary analysis (Table A6 in the appendix) using a difference-indifferences analysis compares out-migration from and immigration to the affected area with migration patterns in the central area of the country. The analysis finds no evidence of different migration patterns to or from the affected area for the total population or the Jewish population.

Finally, women living in northern Israel may have altered their fertility patterns as a response to the war in ways that induce selectivity. For example, the conflict may have motivated healthier (or unhealthier) women to conceive following the war, resulting in a sample of younger siblings being positively (or negatively) selected. To address this possibility, we re-estimate our fixed-effects models excluding siblings born after the war. Note that the disadvantage of using this approach is that exposure is perfectly correlated with birth order: Excluding siblings born after the war will cause control siblings always to be older than treated siblings. Nevertheless, the comparison provides an additional test for robustness. The analysis excluding siblings born after the war, presented in Figure 6, shows the same pattern of effects as those reported in the main analysis. 


\section{Falsification Tests}

As a final assessment of a causal effect of war exposure we conduct two falsification tests, evaluating "placebo" populations unexposed to the war in which the treatment effect should not be observed (or should be weaker). First, to rule out bias resulting from differences between the northern population and rest of the country, we created a temporal placebo-pregnant women with residence in the exposed northern region but who experienced their pregnancies twelve months prior to those exposed to the war (i.e., in 2005 instead of 2006). Second, a geographical placebo was defined to rule out any period-specific source of spuriousness. Women who experienced their pregnancies at the same time as the affected population, but who resided in the natural regions of Tel Aviv, Ramat Gan, Hulon, and Petach Tikva in the center of Israel during the war were selected. These regions are equivalent in size to the exposed population but were not targeted by missiles over the period of observation. Note that we do not expect the effect of the war to be zero among the geographical placebo, because the war arguably induced anxiety throughout the entire Israeli population due to the extensive media coverage and the nationwide draft of young men. Rather, we expect a dose-response effect, with stress much weaker in the center than in the northern regions of the country that were directly threatened by bombs.

Both falsification tests in Figure 7 yield insignificant effects (Table A4 in the appendix). This provides reassurance that the observed birth outcomes should be attributed to war exposure rather than to a spurious demographic or historical determinant of birth outcomes. As expected, the effect on the geographical placebothe population exposed to the war but living the center of the country-is also negative, but it fails to reach significance.

\section{Discussion}

We combine examination of the 2006 Second Lebanon War as a natural experiment with a sibling fixed-effect methodology using a census of Israeli births with no selectivity to evaluate the effect of exposure to an acute environmental stressor on birth outcomes. The findings reveal that gestations exposed to armed conflict in utero have significantly lower birth weights than their unexposed siblings. The negative effect of stress exposure on birth weight is entirely mediated by reduced gestational age rather than fetal growth and occurs in the first and second trimesters of gestation. War exposure does not merely shift birth weight within a plausibly normal range but rather increases the proportion of low-weight births, which are most at risk of health and developmental problems later in life. Given that only within-mother variation is used to identify a causal effect and that exposure is measured at the detailed trimester and month levels, these models offer a sound test of the negative effect of exposure to this environmental stressor.

This analysis both replicates and extends an emerging literature using natural experiments such as natural disaster, terrorist attack, collective mourning, violent conflict, or a spike in discrimination to examine the causal effect of prenatal stress on birth outcomes (Catalano and Hartig 2001; Eskenazi et al. 2007; Lauderdale 2006; 


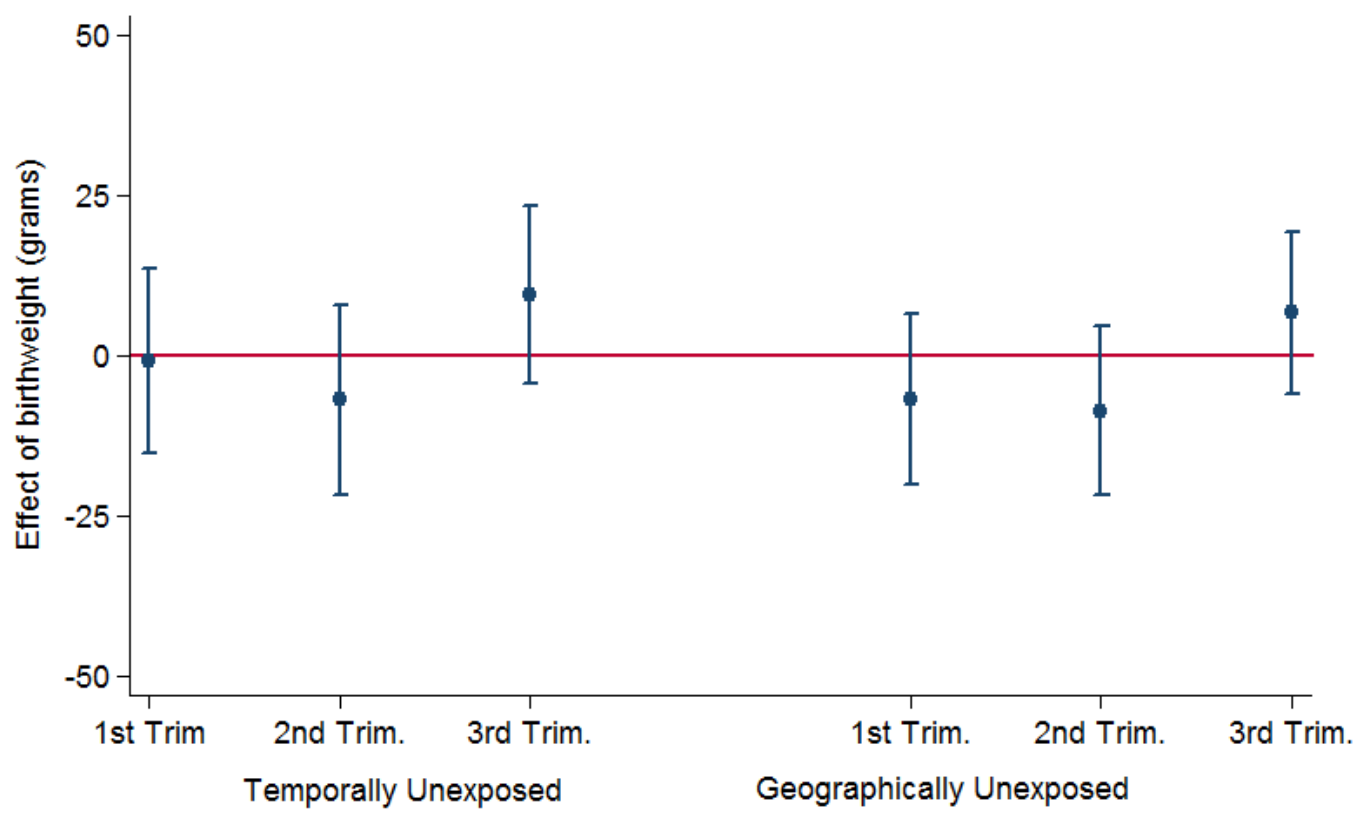

Figure 7: Falsification Tests: Effect on birth weight (grams) of prenatal exposure to the Second Lebanon War across trimester of gestation for geographically and temporally unexposed populations. Shaded dot indicates parameter estimate, and the vertical bar is the 95 percent confidence interval. The temporally unexposed population comprises pregnancies in the northern region of Israel that was hit by missiles, but occurring 12 calendar months prior to pregnancies exposed to the war. The geographically unexposed population identifies pregnancies temporally exposed to the war but located in the metropolitan region of Tel Aviv in the center of the country, which was not targeted by missiles. Sibling fixed-effects linear model. Source: Table A4 in the appendix.

Mansour and Rees 2012; Torche 2011). We offer a non-trivial replication in the sense that we vary the treatment assignment mechanism for stress-using, in this case, the threat of missiles - so that the reasons subjects are spared treatment vary from prior studies (Rosenbaum 2001). In other words, we disrupt the circumstances that elicited stress in prior studies and still find a "tenacious association" (Rosenbaum 2001:223) between exposure to an environmental stressor and birth outcomes. This study also improves upon the research design used in prior scholarship. Prior studies have faced two types of data constraints. Some studies use strong causal inference techniques such as mother's fixed effects but have to rely on survey data with small sample sizes and likely biased retrospective reports of birth weight by the mother (e.g., Mansour and Rees 2012). Other studies use large data sets with no selectivity obtained from birth registries but lack information on siblings and have to rely on population-level comparisons (e.g., Torche 2011; Lauderdale 2006). This study combines the strengths of the two approaches: we use a national census of birth records with no selectivity and can observe multiple births by women. This allows for within-mother, between-sibling comparisons, providing a stronger account for unobserved mother's confounders. The availability of a large data set also allows us to examine the timing of the effect of stress exposure at the detailed 
trimester and month levels, illuminating the time-specific physio-neuroendocrine mechanisms involved.

This study also faces important limitations that invite further research. First, we cannot fully exclude alternative pathways of influence linking war exposure to birth outcomes. For example, healthcare facilities may have prioritized readiness for the consequences of an attack rather than prenatal care, or transportation may have been hindered, hampering access to medical facilities. Exhaustive evaluation of the consequences of the war by an ad hoc independent committee suggests these spillover effects did not materialize (Winogard et al. 2008), but we cannot rule them out in a natural setting. Beyond this particular case, the challenge of ruling out all alternative pathways of interest is a central limitation in the use of natural experiments outside of the controlled conditions of the laboratory. Because they occur in natural settings, natural experiments are high in external validity, but there are limits to the ability to control all their possible corollaries. We strove to find a distinctive armed conflict with minimal spillover effects among a well defined population, but this setting certainly cannot match the standards of manipulation and control achieved in the laboratory.

Another limitation of this study is the impossibility of ascertaining the specific mechanisms linking stress exposure to observed birth outcomes. Theory and prior research suggest neuroendocrine, vascular, inflammation/infection and behavioral responses as plausible mechanisms, but data currently available do not allow us to evaluate their relative importance. Other kinds of approaches are better suited to addressing this question. Measuring mechanisms requires careful evaluation of biomarkers and behavioral responses among smaller, continuously monitored samples which is very hard to achieve in the examination of large, representative populations.

This analysis has proceeded under the implicit assumption that the effect of war exposure for each exposed woman did not depend on others being exposed to the war or experiencing stress as a result of exposure. This assumption, known as "no interference" (Rubin 1980) is most likely violated in this and most social settings in which networks of influence and interaction link individuals exposed to an environmental stressor. Processes of social interaction and influence likely contribute to spreading and exacerbating fear and anxiety and/or providing sources of support and coping. Modeling such processes is challenging as it would require measures of the scope, strength, and content of networks of influence among both affected and unaffected populations, but it is an important task that this study invites and that social scientists are particularly well equipped to undertake.

Finally, this analysis focuses on birth outcomes. While birth outcomes are important in their own right, they capture endowments at the starting gate of life only. To the extent that birth weight predicts health, developmental, and socioeconomic outcomes the consequences of prenatal stress may extend over the entire life cycle. A natural next step for social scientists is examining what happens next-how prenatal exposure to plausible exogenous sources of stress shapes trajectories of health and wellbeing over the life course and the role that initial effects on birth outcomes play in this process. 


\section{Notes}

1 This definition was chosen over the more intuitive one of infants born before the war because restricting the sample to those born before the war would exclude premature births occurring before the war that would have been exposed if they had not been premature. Their exclusion would artificially increase the observed birth weight of infants exposed to the war late in the pregnancy, because they would be an increasingly selected group that excludes preterm births.

\section{References}

Almond, Douglas, Hilary W. Hoynes, and Diane W. Schanzenbach. 2011. "Inside the War on Poverty: The Impact of Food Stamps on Birth Outcomes." Review of Economics and Statistics 93(2):387-403. http://dx.doi.org/10.1162/REST_a_00089.

Alon, Gideon, Assaf Oni, Aloof Ben, and Yoav Shtern. 2006. “Nassarallah: We wouldn't have abduct the two soldiers had we known it would lead to war." Haaretz, August 27. http://www.haaretz.co.il/misc/1.1131753.

Austin, Marie-Paule and Leo Leade, 2000. Maternal stress and obstetric and infant outcomes: Epidemiological findings and neuroendocrine mechanisms. Australian and New Zealand Journal of Obstetrics and Gynaecology 40:331-337. http://dx . doi .org/10 .1111/j . 1479-828X.2000.tb03344.x.

Barker, David J. P., Godfrey, Keith. M., Gluckman, Peter D., Harding, Jane E., Owens, Julie A., and Robinson, Jeffrey S. 1993. "Fetal nutrition and cardiovascular disease in adult life." Lancet 341:938-941. http://dx . doi .org/10 .1016/0140-6736 (93) 91224-A.

Batley, Nicholas J., Jihad Makhoul, and Sanna A. Latif. 2008. “War as a positive medical educational experience." Medical Education 42(12):1166-71. http://dx.doi.org/10. $1111 / \mathrm{j} .1365-2923.2008 .03228$. $\mathrm{x}$.

Behrman, Jere and Mark Rosenzweig. 2004. "The returns to birth weight." The Review of Economics and Statistics 86:586-601.

Behrman, Richard E. and Adrienne Stith-Butler. 2007. Preterm Birth: Causes, Consequences, and Prevention. Washington: National Academies Press.

Beydoun, Hind and Audrey F. Saftlas. 2008. "Physical and mental health outcomes of prenatal maternal stress in human and animal studies: a review of recent evidence." Paediatric and Perinatal Epidemiology 22(5):438-66. http://dx.doi.org/10.1111/j.1365-3016. 2008.00951.x.

Boardman, Jason, Daniel Powers, Yolanda Padilla and Robert Hummer. 2002. "Low birth weight, social factors, and developmental outcomes among children in the United States." Demography 39:353-368. http://dx.doi.org/10.1353/dem.2002.0015.

Bruckner, Tim and Robert Catalano. 2007. "The sex ratio and age-specific male mortality: Evidence for culling in Utero." American Journal of Human Biology 19(6):763-73. http: //dx.doi.org/10.1002/ajhb. 20636.

Catalano, Ralph, Tim Bruckner, Amy R. Marks, and Brenda Eskenazi. 2006. “Exogenous shocks to the human sex ratio: the case of September 11, 2001 in New York City." Human Reproduction 21(12):3127-31. http://dx . doi .org/10.1093/humrep/del283.

Catalano, Ralph and Terry Hartig. 2001. "Communal bereavement and the incidence of very low birth weight in Sweden." Journal of Health and Social Behavior 42(4):333-41. http://dx.doi.org/10.2307/3090182. 
Chodick, Gabriel, Varda Shalev, Iris Goren, and Peter D. Inskip. 2007. "Seasonality in birth weight in Israel: New evidence suggests several global patterns and different etiologies." Annals of Epidemiology 17(6):440-46. http://dx.doi .org/10.1016/j .annepidem. 2006. 10.013.

Cohen, Miri. 2008. “Acute Stress Disorder in older, middle-aged and younger adults in reaction to the second Lebanon war." International Journal of Geriatric Psychiatry 23(1):3440. http://dx.doi.org/10.1002/gps.1832.

Conley, Dalton, Kate Strully, and Neil Bennett. 2003. The starting gate: Birth weight and life chances. Berkeley: University of California Press.

Coussons-Read, Mary, Michele Okun, Mischel Schmitt, and Scott Giese. 2005. "Prenatal stress alters cytokine levels in a manner that may endanger human pregnancy." Psychosomstic Medicine 67(4):625-31. http://dx . doi .org/10.1097/01 .psy.0000170331.74960 . ad.

De Weerth, Carolina and Jan K. Buitelaar. 2005. "Physiological stress reactivity in human pregnancy-a review." Neuroscience Biobehavioral Reviews 29(2):295-312. http://dx. doi . org/10.1016/j.neubiorev.2004.10.005.

Dohrenwend, Barbara S. and Bruce P. Dohrenwend. 1970. “Class and race as status-related sources of stress." Pp. 111-39 in Social Stress, edited by S. Levine and N. Scotch. Chicago: Aldine.

Dunkel Schetter, Christine. 2011. "Psychological science on pregnancy: stress processes, biopsychosocial models, and emerging research issues." Annual Review of Psychology 62:531-58. http://dx.doi.org/10.1146/annurev.psych.031809.130727.

Dunkel Schetter, Christine and Laura. Glynn. 2011. "Stress in pregnancy: Empirical evidence and theoretical issues to guide interdisciplinary research." Pp. 321-343 in The Handbook of Stress Science: Biology, Psychology, and Health, edited by R. Contrada and A. Baum. New York: Springer.

Elenkov, Ilia J., Elizabeth L. Webster, David J. Torpy, and George P. Chrousos. 1999. “Stress, corticotropin-releasing hormone, glucocorticoids, and the immune/inflammatory response: acute and chronic effects." Annals of the New York Academy of Science 876:1-13. http://dx.doi.org/10.1111/j.1749-6632.1999.tb07618.x.

Eskenazi, Brenda, Amy R. Marks, Ralph Catalano, Tim Bruckner, and Paolo G. Toniolo. 2007. "Low birth weight in New York city and upstate New York following the events of September 11th." Human Reproduction 22(11):3013-20. http://dx.doi .org/10.1093/ humrep/dem301.

Feder, Adriana, Eric J. Nestler, and Dennis S. Charney. 2009. "Psychobiology and molecular genetics of resilience." Nature Reviews Neuroscience 10(6):446-57. http://dx.doi . org/10. $1038 / \mathrm{nrn} 2649$.

Ghanem, As'ad. 1998. "State and minority in Israel: the case of ethnic state and the predicament of its minority." Ethnic and Racial Studies 21(3):428-48. http://dx.doi.org/10. 1080/014198798329892.

Giles, Warwick B., Mark McLean, Joanne J. Davies, and Roger Smith. 1996. "Abnormal umbilical artery Doppler waveforms and cord blood corticotropin-releasing hormone." Obsteterics $\mathcal{E}$ Gynecology 87(1):107-11. http: //dx . doi .org/10.1016/0029-7844 (95) 00338-X.

Glynn, Laura M., Pathik D. Wadhwa, Christine Dunkel-Schetter, Aleksandra Chicz-DeMet, and Curt A. Sandman. 2001. "When stress happens matters: Effects of earthquake timing on stress responsivity in pregnancy." American Journal of Obstetrics and Gynecology 184(4):637-42. http://dx.doi.org/10.1067/mob.2001.111066. 
Goldenberg, Robert L., John C. Hauth, and William W. Andrews. 2000. "Intrauterine infection and preterm delivery." The New England Journal of Medicine 342(20):1500-7. http://dx.doi.org/10.1056/NEJM200005183422007.

Hobel, Calvin, and Jennifer Culhane. 2003. "Role of psychosocial and nutritional stress on poor pregnancy outcome." Journal of Nutrition 133(5 Suppl 2):1709S-17S.

Hobel, Calvin," Amy Goldstein, and Emily S. Barrett. 2008. "Psychosocial stress and pregnancy outcome." Clinical Obstetrics \& Gynecology 51(2):333-48. http://dx. doi .org/10. $1097 /$ GRF . Ob013e31816f2709.

Holmes, Thomas and Richard Rahe. 1967. "Social Readjustment Rating Scale." Journal of Psychosomatic Research 11(213-218). http://dx.doi.org/10.1016/0022-3999(67)90010-4.

Holzman, Claudia, James Jetton, Theresa Siler-Khodr, Rachel Fisher, and Tanya Rip. 2001. "Second trimester corticotropin-releasing hormone levels in relation to preterm delivery and ethnicity." Obstetetrics \& Gynecology 97(5 Pt 1):657-63. http://dx . doi . org/10 . 1016/ S0029-7844(00)01209-6.

Hoynes, Hilary, Marianne Page, and Ann H. Stevens. 2011. "Can targeted transfers improve birth outcomes? Evidence from the introduction of the WIC program." Journal of Public Economics 95(7-8):813-27. http://dx.doi.org/10.1016/j.jpubeco.2010.12.006.

Israel State Comptroller. 2007. Preparation and Functioning of the Hinterland in the Second Lebanon War. The Full Report. Jerusalem: The State Comptroller.

Kirschbaum, Clemens, Jens C. Prussner, Arthur A. Stone, Ilona Federenko, Jens Gaab, Doris Lintz, Nicole Schommer, and Dirk H. Hellhammer. 1995. "Persistent High Cortisol Responses to Repeated Psychological Stress in a Subpopulation of Healthy Men." Psychosomatic Medicine 57(5):468-74. http://dx.doi.org/10.1097/ 00006842-199509000-00009.

Knudsen, Eric I., James J. Heckman, Judy L. Cameron, and Jack P. Shonkoff. 2006. “Economic, neurobiological, and behavioral perspectives on building America's future workforce." Proceedings of the National Academy of Sciences of the United States of America 103(27):1015562. http://dx.doi.org/10.1073/pnas.0600888103.

Lauderdale, Diane. 2006. "Birth outcomes for Arabic-named women in California before and after September 11." Demography 43:185-201. http://dx. doi.org/10.1353/dem. 2006. 0008.

Lewin-Epstein, Noah and Moshe Semyonov. 1992. "Local-Labor Markets, Ethnic Segregation, and Income Inequality." Social Forces 70(4):1101-19. http://dx.doi .org/10.1093/sf/ 70.4.1101.

Lobel, Marcj, Dolores L. Cannella, Jennifer E. Graham, Carla DeVincent, Jayne Schneider, and Bruce A. Meyer. 2008. "Pregnancy-specific stress, prenatal health behaviors, and birth outcomes." Health Psychoogyl 27(5):604-15. http://dx. doi .org/10.1037/a0013242.

Lockwood, Charles J. 1999. "Stress-associated preterm delivery: The role of corticotropinreleasing hormone." American Journal of Obstetrics and Gynecology 180(1):S264-S66. http: //dx.doi.org/10.1016/S0002-9378(99)70713-1.

Mansour, Hani and Daniel Rees. 2012. "Armed conflict and birth weight: Evidence from the al-Aqsa Intifada." Journal of Development Economics 99:190-99. http://dx. doi .org/10 . 1016/j.jdeveco.2011.12.005.

McDowall, David, Richard McCleary, Errol Meidinger, and Richard Hay. 1980. Interrupted Time-Series Analysis Thousand Oaks, CA.: Sage.

McEwen, Bruce S. 1998. "Stress, adaptation, and disease. Allostasis and allostatic load." Annals of the New York Academy of Science 840:33-44. http://dx.doi.org/10.1111/j. 1749-6632.1998.tb09546.x. 
McEwen, Bruce S. and Eliot Stellar. 1993. "Stress and the Individual-Mechanisms Leading to Disease." Archives of Internal Medicine 153(18):2093-101. http://dx . doi .org/10 . 1001/ archinte.1993.00410180039004.

McLean, Mark, Andrew Bisits, Joanne Davies, Russell Woods, Philip Lowry, and Roger Smith. 1995. "A placental clock controlling the length of human pregnancy." Nature Medicine 1(5):460-3. http://dx.doi.org/10.1038/nm0595-460.

Milad, Magdy. 1998. "Stress and anxiety do not result in pregnancy wastage." Human Reproduction 12:2296-300. http://dx.doi .org/10.1093/humrep/13.8.2296.

Neggers, Yasmin, Robert Goldenberg, Suzanne Cliver, and John Hauth. 2006. "The relationship between psychosocial profile, health practices, and pregnancy outcomes." Acta Obstetricia et Gynecologica Scandinavica 85(3):277-85. http://dx . doi .org/10 . 1080/ 00016340600566121.

Nelson, Deborah B., Jeanne A. Grisso, Marshall M. Joffe, Colleen Brensinger, Leslie Shaw, and Elizabeth Datner. 2003. "Does stress influence early pregnancy loss?" Annals of Epidemiology 13(4):223-9. http://dx . doi .org/10 . 1016/S1047-2797 (02) 00419-2.

Nepomnaschy, Pablo A., Kathleen B. Welch, Daniel S. McConnell, Bobbi S. Low, Beverly I. Strassmann, and Barry G. England. 2006. "Cortisol levels and very early pregnancy loss in humans." Proceedings of the National Academy of Sciences of the United States of America 103(10):3938-42. http://dx.doi.org/10.1073/pnas.0511183103.

Okun, Barbara S. and Dov Friedlander. 2005. "Educational stratification among Arabs and Jews in Israel: Historical disadvantage, discrimination, and opportunity." Population Studies-A Journal of Demography 59(2):163-80. http://dx.doi.org/10.1080/ 00324720500099405.

Palloni, Alberto. 2006. "Reproducing inequalities: luck, wallets, and the enduring effects of childhood health." Demography 43(4):587-615. http://dx.doi .org/10.1353/dem. 2006. 0036.

Palmieri, Patrick A., Daphna Canetti-Nisim, Sandro Galea, Robert J. Johnson, and Stevan E. Hobfoll. 2008. "The psychological impact of the Israel-Hezbollah War on Jews and Arabs in Israel: The impact of risk and resilience factors." Social Science $\mathcal{E}$ Medicine 67(8):1208-16. http://dx.doi.org/10.1016/j.socscimed.2008.06.030.

Paneth, Nigel S. 1995. "The problem of low birth weight." Future of Children 5(1):19-34. http://dx.doi.org/10.2307/1602505.

Pearlin, Leonard. 1999. “The stress process revisited." Pp. 395-415 in Handbook of the Sociology of Mental Health, edited by C. Aneshensel and J. Phelan. New York: Academic/Plenum.

Pearlin, Leonard. I., Elizabeth G. Menaghan, Morton A. Lieberman, and Joseph T. Mullan. 1981. "The Stress Process." Journal of Health and Social Behavior 22(4):337-56. http: //dx.doi.org/10.2307/2136676.

Reichman, Nancy E. and Julien O. Teitler. 2003. "Effects of psychosocial risk factors and prenatal interventions on birth weight: Evidence from New Jersey's HealthStart program." Perspectives on Sexual and Reproductive Health 35(3):130-37. http : / dx . doi . org/10.1111/ j.1931-2393.2003.tb00133.x.

Rosenbaum, Paul. 2001. "Replicating effects and biases." The American Statistician 55(3):223227. http://dx.doi.org/10.1198/000313001317098220.

Rubin, Donald. 1980. "Discussion of 'Randomization analysis of experimental data in the Fisher randomization test' by Basu." Journal of the American Statistical Association 75:591-593.

Selye, Hans. 1956. The Stress of Life. New York: McGraw-Hill. 
Seckl, Jonathan. 1998. "Physiologic Programming of the Fetus" Clinics in Perinatalogy 25:939_ 964.

Semyonov, Moshe and Noah Lewin-Epstein. 2011. "Wealth Inequality: Ethnic Disparities in Israeli Society." Social Forces 89(3):935-59. http://dx.doi.org/10.1353/sof. 2011. 0006.

Shonkoff, Jack 2010. "Building a New Biodevelopmental Framework to Guide the Future of Early Childhood Policy." Child Development 81(1):357-367. http://dx.doi .org/10 . $1111 / j .1467-8624.2009 .01399 . x$.

Thoits, Peggy A. 1983. "Dimensions of Life Events that Influence Psychological Distress: An Evaluation and Synthesis of the Literature." Pp. 33-103 in Psychosocial Stress: Trends in Theory and Research, edited by H. Kaplan. New York: Academic Press. http://dx. doi . org/10.1016/B978-0-12-397560-7.50007-6.

- 2010. "Stress and Health: Major Findings and Policy Implications." Journal of Health and Social Behavior 51:S41-S53. http://dx. doi .org/10.1177/0022146510383499.

Talge, Nicole, Charles Neal, and Vivette Glover. 2007. “Antenatal maternal stress and longterm effects on child neurodevelopment: how and why?" Journal of Child Psychology and Psychiatry 48(3/4):245-261. http://dx.doi.org/10.1111/j.1469-7610.2006.01714.x.

Torche, Florencia.. 2011. "The Effect of Maternal Stress on Birth Outcomes: Exploiting a Natural Experiment." Demography 48(4):1473-91. http://dx.doi .org/10.1007/ s13524-011-0054-z.

Torche, Florencia and Andres. Villarreal. 2014. "Prenatal Exposure to Violence and Birth Weight in Mexico: Selectivity, Exposure, and Behavioral Responses" American Sociological Review 79(5):966-92. http://dx.doi .org/10.1177/0003122414544733.

Turner, R. Jay. 2003. "The pursuit of socially modifiable contingencies in mental health." Journal of Health and Social Behavior 44(1):1-17.

-. 2010. "Understanding health disparities: The promise of the stress process model." Pp. 3-21 in Advances in the conceptualization of the stress process: Essays in honor of Leonard I. Pearlin, edited by W. Avison, S. Aneshensel, S. Schieman, and B. Wheaton. New York: Springer.

Turner, R. Jay. and William R. Avison. 2003. "Status variations in stress exposure: Implications for the interpretation of research on race, socioeconomic status, and gender." Journal of Health and Social Behavior 44(4):488-505. http: //dx . doi .org/10 . 2307/1519812.

Turner, R. Jay, Blair Wheaton, and Donald A. Lloyd. 1995. "'"The Epidemiology of Social Stress." American Sociological Review 60(1):104-25. http://dx.doi.org/10.2307/ 2096348.

Wadhwa, Pathik D., Thomas J. Garite, Maneul Porto, Laura Glynn, Aleksandra ChiczDeMet, Christine Dunkel-Schetter, and Curt A. Sandman. 2004. "Placental corticotropinreleasing hormone $(\mathrm{CRH})$, spontaneous preterm birth, and fetal growth restriction: A prospective investigation." American Journal of Obstetrics and Gynecology 191(4):1063-69. http://dx.doi.org/10.1016/j.ajog.2004.06.070.

Wheaton, Blair. 1997. "The nature of chronic stress." Pp. 43-73 in Coping with chronic stress. The Plenum series on stress and coping, edited by B. Gotlieb. New York: Plenum Press. http://dx.doi.org/10.1007/978-1-4757-9862-3_2.

Winograd, Eliyahu, Ruth Gavison, Isekiel Dror, Haim Nadal, and Menahem Eitan. 2008. The Second Lebanon War: Final Report. Jerusalem: The State of Israel.

Yahav, Rivka and Miri Cohen. 2007. "Symptoms of acute stress in Jewish and Arab Israeli citizens during the Second Lebanon War." Social Psychiatry and Psychiatric Epidemiology 42(10):830-36. http://dx.doi.org/10.1007/s00127-007-0237-5. 
Acknowledgements: The authors thank Dvorit Angel of the Israeli Central Bureau of Statistics for preparing the data sets used in this study and Uri Goldstein for excellent research assistantship. We are also grateful to Yinon Cohen and Seymour Spilerman for helpful comments and suggestions.

Florencia Torche: Department of Sociology, New York University.

E-mail: florencia.torche@nyu.edu.

Uri Shwed: Department of Sociology and Anthropology, Ben Gurion University of the Negev.

E-mail: shwed@bgu.ac.il. 